\title{
Implementasi Model Pembelajaran BCCT (Beyond Centers And Circle Times) dan Model Pembelajaran Konsiderasi di TK Khalifah Baciro Kota Yogyakarta
}

\author{
Raudatul Hasanah' ${ }^{1}$ Muhammad Abdul Latif ${ }^{2}$ \\ 1UIN Sunan Kalijaga Yogyakarta, raudulhasanah80@gmail.com \\ 2UIN Sunan Kalijaga Yogyakarta, abdullatif.ful@gmail.com
}

\begin{abstract}
ABSTRAK
Penelitian ini bertujuan untuk memberikan gambaran pelaksanaan model pembelajaran BCCT dan model pembelajaran konsiderasi di TK Khalifah Baciro Kota Yogyakarta. Metode penelitian ini menggunakan jenis penelitian kualitatif. Subjek penelitian penelitian ini adalah 4 guru kelas, 1 kepala sekolah dan 36 anak didik. Pengumpulan data menggunakan observasi, wawancara, dan dokumentasi. Adapun analisis data menggunakan Model Milles Huberman. Adapun uji keasbsahannya menggunakan triangulasi teknik dan sumber. Hasil penelitian menunjukkan bahwa model pembelajaran BCCT dan konsiderasi dapat dijadikan rujukan bagi lembaga Pendidikan Anak Usia dini sebagai upaya mengembangkan aspek-aspek perkembangan anak yang kreatif dan inovatif. Selain itu, model pembelajaran konsiderasi dapat membentuk akhlakul karimah anak, seperti sopan santun, berbudi pekerti dan berperilaku baik.

Kata Kunci: Pembelajaran BCCT, Pembelajaran Konsiderasi, Anak Usia Dini
\end{abstract}

\begin{abstract}
This study aims to provide an overview of the implementation of the BCCT learning model and the consideration learning model in TK Khalifah Baciro, Yogyakarta City. This research method uses qualitative research. The subjects of this research were 4 class teachers, 1 school principal and 36 students. Data collection uses observation, interviews, and documentation. The data analysis uses the Huberman Milles Model. The authenticity test uses triangulation of techniques and sources. The results showed that the BCCT learning model and consideration can be used as a reference for early childhood education institutions as an effort to develop aspects of creative and innovative child development. In addition, considerations of the learning model can shape the character of the child's mercy, such as manners, good character and good behavior.
\end{abstract}

Keywords: BCCT Learning, Consideration Learning, Early Childhood 
Al-Mudarris : Jurnal Ilmiah Pendidikan Islam Vol. 2, No. 2, November 2019, pp. 184 - 199

\section{PENDAhUluan}

Model BCCT (Beyond Centre dan Circle Time) atau yang biasa disebut dengan Senling (Model Sentra dan Lingkaran) ialah model pembelajaran yang digunakan untuk melatih perkembangan anak dengan menggunakan metode bermain (Wibowo, 2012:63). Pendekatan sentra dan lingkungan berfokus pada anak. Pembelajarannya berpusat di sentra main dan saat anak dalam lingkaran. Sebelum melakukan kegiatan anak diajak duduk melingkar bersama guru. Pada saat dalam lingkaran guru memberikan pijakan (scaffolding) sebelum kegiatan, saat kegiatan, dan sesudah kegiatan (Depdiknas, 2006:6). Sejak tahun 70-an Pamela Phelps di Florida, Amerika Serikat mulai mengembangkan model pembelajaran sentra yang kemudian oleh drg. Wismiarti Tamin diadopsi. Beliau adalah seorang pendiri sekolah Al-Falah di Ciracas, Jakarta Timur pada tahun 1996. Di Indonesia BCCT pertama kali diadaptasi oleh
p-ISSN: 2622-1993

e-ISSN: 2622-1586

lembaga PAUD yang berlatar belakang Islam. Nibras OR Salim adalah seorang pimpinan TK Istiqlal Jakarta yang pernah studi banding di Creative Pre School di Tallahasse, Florida, AS pada tahun 1996 (Anam, 2007:118).

Di Indonesia model pembelajaran $B C C T$ lebih dikenal dengan model pembelajaran sentra. Terdapat 7 kegiatan bermain melalui sentra, yaitu sentra bahan alam, sentra seni, sentra balok, sentra persiapan, sentra imtak, sentra main peran besar, dan sentra main peran kecil (Saleh, 2010:7).

Model pembelajaran konsiderasi sesuai dengan teori belajar humatistik. Menurut Carl Rogers aplikasi teori humanistik terhadap pembelajaran siswa lebih menunjuk pada ruh atau spirit selama proses pembelajaran yang mewarnai metode-metode yang diterapkan. Teori belajar humanistik lebih menekankan perlunya sikap saling menghargai dan tanpa prasangka (antara klien dan terapis) dalam membantu individu mengatasi 
Al-Mudarris : Jurnal Ilmiah Pendidikan Islam Vol. 2, No. 2, November 2019, pp. 184 - 199

masalah-masalah kehidupannya (Gunawati dkk, 2018:132). Model ini menekankan pada strategi pembelajaran yang dapat membentuk kepribadian. Tujuannya adalah agar siswa menjadi manusia yang memiliki kepedulian terhadap orang lain. Kebutuhan yang fundamental pada manusia adalah bergaul secara harmonis dengan orang lain, saling memberi dan menerima dengan penuh cinta dan kasih sayang "to love and to be loved". Dengan demikian, pembelajaran sikap pada dasarnya adalah membantu anak agar dapat mengembangkan kemampuan untuk bisa hidup bersama secara harmonis, peduli, dan merasakan apa yang dirasakan orang lain (tepo saliro) (Sanjaya, 2010:279).

Selaras dengan pendapat di atas, Mohammad Syafei melalui Lembaga Pendidikan Kayutanam di Sumatra Barat, menolak model pendidikan barat yang hanya menekankan aspek kognitif. Syafei menginginkan peserta didiknya menjadi seorang ideal, yakni tertanam cita kebenaran dalam hatinya, dalam pengetahuan intelektualnya, dan dalam perilakunya sehari-hari. Syafei merupakan putra Marah Sultan, tokoh pergerakan politik NIP di Padang, yang melanjutkan cita-cita perjuangan orang tuanya dalam bidang pendidikan. Pendidikan yang dibangunnya dapat mehasilkan manusia yang rajin dan ulet, serta memiliki kecakapan yang diperlukan sebagai bangsa yang bermartabat, dan memiliki kecintaan terhadap tanah air dan sesama manusia (Mulyasa, 2014:68).

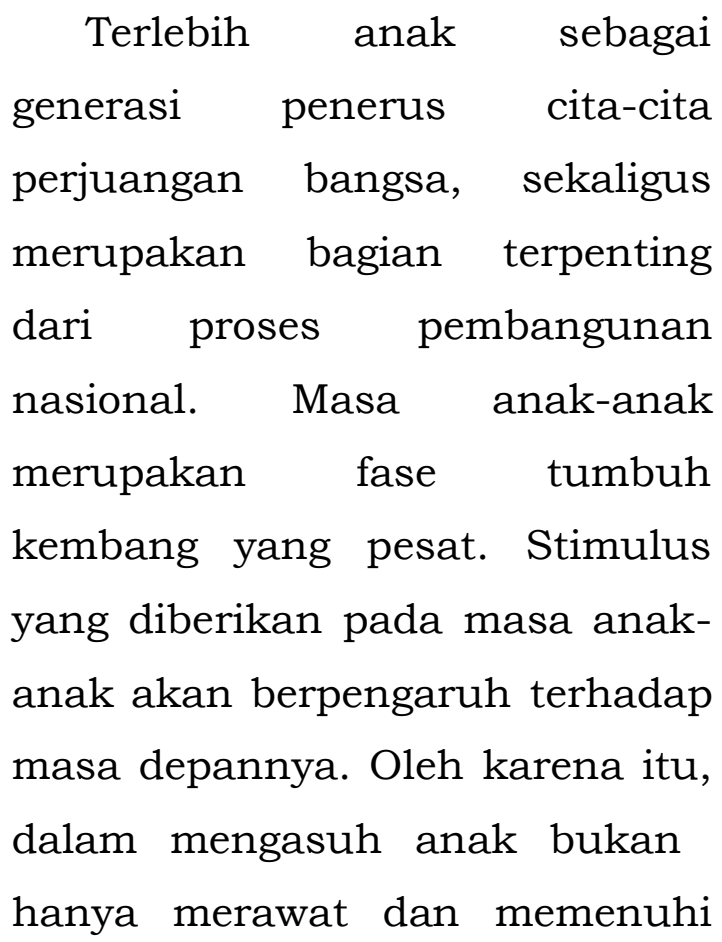
generasi penerus cita-cita perjuangan bangsa, sekaligus dari proses pembangunan nasional. Masa anak-anak merupakan fase tumbuh kembang yang pesat. Stimulus anak akan berpengaruh terhadap masa depannya. Oleh karena itu, hanya merawat dan memenuhi 
Al-Mudarris : Jurnal Ilmiah Pendidikan Islam Vol. 2, No. 2, November 2019, pp. 184 - 199

segala kebutuhan fisik akan tetapi memersiapkan anak agar dapat hidup bermasyarakat.

Pentingnya dalam mempersiapkan generasi penerus bangsa maka diperlukan suatu model pembelajaran yang baik. Sebagaimana penelitian terdahulu yang relevan, model pembelajaran BCCT sangat efektif agar anak kreatif dan inovatif serta mengembangkan enam aspek perkembangan anak (kognitif, bahasa, seni, fisikmotorik, sosial-emosional dan nilai agama moral) (Hamzah, 2016:119), serta pembelajaran BCCT ini dapat berjalan secara optimal dalam membantu menstimulus pada Taman Pendidikan Al Quran (Aziz, 2017:14).

Selanjutnya pada model pembelajaran konsiderasi sangat efektif melatih moral anak (Suharto, 2018), ketrampilan sosial anak (Yulida, 2018:21), membantu afektif anak (Prianggita, 2016:80), berpengaruh positif terhadap pola hidup bersih dan sehat anak (Gustini, 2011).

Di Yogyakarta model pembelajaran $\quad B C C T$ dan konsiderasi sebagian lembaga PAUD sudah menerapkan model pembelajaran tersebut. TK Khalifah Baciro Kota Yogyakarta adalah salah satu lembaga yang menerapkan model BCCT dan konsiderasi untuk mengembangkan seluruh perkembangan anak.

Berdasarkan uraian di atas penelitian ini bertujuan untuk mengkaji tentang Implementasi Model Pembelajaran BCCT (Beyond Centre dan Circle Time) dan Konsiderasi di TK Khalifah Baciro Kota Yogyakarta.

\section{METODE}

Jenis penelitian yang digunakan adalah penelitian lapangan (field research) dengan menggunakan pendekatan kualitatif. Metode kualitatif sebagai prosedur penelitian yang menghasilkan data deskriptif berupa kata-kata tertulis atau lisan dari orang-orang dan 
Al-Mudarris : Jurnal Ilmiah Pendidikan Islam Vol. 2, No. 2, November 2019, pp. 184 - 199

perilaku yang diamati (Moleong, 2017:3).

Subjek penelitian ialah Guru Kelas (4 orang), Kepala Sekolah (1 orang) dan Anak (37 orang), di TK Khalifah Baciro Kota Yogyakarta. Objek adalah apa yang akan diselidiki dalam kegiatan penelitian. Menurut Nyoman Kutha Ratna objek adalah keseluruhan gejala yang ada disekitar kehidupan manusia (Prastowo, 2011). Apabila dilihat dari sumbernya, objek dalam penelitian kualitatif menurut Spradley disebut social situation atau situasi sosial yang terdiri dari tiga elemen, yaitu tempat, pelaku, dan aktivitas yang berinteraksi secara sinergis (Sugiyono, 2017:49). Teknik pengumpulan data yang digunakan adalah observasi partisipasi aktif, wawancara semi struktur, dan dokumentasi. Penelitian ini menggunakan model analisis data interaktif dari Miles dan Huberman, teridir atas reduksi data, penyajian data/ data display dan menarik kesimpulan/ verifikasi. Uji keabsahan data penelitian ini menggunakan triangulasi sumber dan triangulasi teknik.

\section{HASIL DAN PEMBAHASAN}

\section{A. Model Pembelajaran BCCT (Beyond Centre dan Circle Time)}

Model pembelajaran $B C C T$ (Beyond Centre dan Circle Time) atau model pembelajaran sentra dan lingkaran merupakan model pembelajaran yang sinergis dengan strategi belajar sambil bermain. Model BCCT sendiri lahir dari serangkaian pembahasan di Creative Center for Childhood Research an Training (CCCRT) di Florida, Amerika Serikat. CCCRT meramu kajian teoritik dan pengalaman empirik dari berbagai pendekatan. Dari Montessori, Highscope, Head Start, dan Regio Emilia. CCCRT dalam kajiannya telah diterapkan di Creativi Pre School selama lebih dari 33 tahun, baik untuk anak normal maupun anak dengan kebutuhan khusus. Model BCCT ini merupakan pengembangan dari 
Al-Mudarris : Jurnal Ilmiah Pendidikan Islam Vol. 2, No. 2, November 2019, pp. 184 - 199

model Montessori, Highscope, dan Regio Emilio (Mursid, 2017:155).

B. Penerapan Pembelajaran dalam Model BCCT di TK Khalifah

TK Khalifah Baciro merupakan salah satu TK yang menerapkan model pembelajaran BCCT (beyond centers and circle time). TK Khalifah memiliki motto yaitu "Tauhid dan Entrepreneur". TK Khalifah bertekad untuk menjadikan siswa-siswi TK Khalifah menjadi Entrepreneur yang bertauhid. Metode pembelajaran "Learning by Playing" dengan sistem "moving class" dengan 5 sentra yang tersedia (tauhid, lifeskill, art, sains dan exercise). TK Khalifah menggunakan 5 sentra sesuai dengan kebutuhan sekolah yang sesuai dengan tujuan sekolah tersebut. Untuk lebih jelasnya akan dijelaskan apa yang dimaksud 5 sentra tersebut dan apa yang dipelajaran dalam sentra-sentra tersebut.

\section{Sentra Tauhid}

Sentra tauhid sama dengan sentra imtaq atau keagamaan.
p-ISSN: 2622-1993

e-ISSN: 2622-1586

Sentra tauhid adalah sentra yang mengenalkan atribut berbagai agama, sikap menghormati agama. Kegiatan yang dilaksanakan adalah menanamkan nilai-nilai kehidupan beragama, keimanan, dan ketakwaan kepada Allah Swt. Berikut ini adalah kegiatan yang dilaksanakan dalam sentra tauhid, yaitu:

1) Mengajarkan kalimat tauhid hidayah dari Allah Swt.

2) Mengajarkan bacaan-bacaan sholat.

3) Mengajarkan surah-surah dan hadits pendek serta doadoa harian.

4) Menghafal surah-surah pendek, asmaul husna dan doa harian.

5) Mengajarkan bersedekah sebagai bentuk wujud mensyukuri nikmat Allah Swt dan peduli sesama.

6) Praktek puasa sunnah seninkamis untuk kelompok besar.

7) Menanamkan kecintaan kepada Nabi Muhammad Saw dan sahabat.

8) Dan lain-lain. 
Al-Mudarris : Jurnal Ilmiah Pendidikan Islam Vol. 2, No. 2, November 2019, pp. 184 - 199

\section{Sentra Lifeskill}

Sentra lifeskill atau sentra keterampilan hidup merupakan sentra yg mengajarkan keterampilan hidup kepada anak. Melalui sentra lifeskill anak diajarkan berbagai keterampilan atau kemampuan untuk dapat berperilaku positif dan beradaptasi dengan lingkungan memungkinkan seseorang mampu menghadapi berbagai tuntutan dan tantangan dalam hidupnya sehari-hari secara efektif.

Lifeskill atau keterampilan hidup adalah interaksi berbagai pengetahuan dan kecakapan yang sangat penting dimiliki seseorang sehingga mereka dapat hidup mandiri. TK Khalifah Baciro membuat kegiatan aktif bagi anak-anak untuk menciptakan pengalaman menarik dan mengasyikkan dari konsep etos kerja yang ingin diterapkan pada anak, diantaranya disiplin, mandiri, mau berusaha, dan tidak mudah menyerah.
p-ISSN: 2622-1993

e-ISSN: 2622-1586

Berikut ini adalah beberapa kegiatan yang pernah guru lakukan untuk menstimulus kemauan dan kemampuan anakanak dalam ketrampilan hidup yang menurut TK Khalifah perlu anak-anak miliki:

1) Berwudhu dan Mempelajari gerakan sholat.

2) Memasang kancing baju.

3) Memakai dan melepas sepatu sendiri.

4) Setrika dan melipat baju.

5) Menjahit.

6) Menyapu lantai dan membenahi ruangan kelas mereka.

7) Bermain peran (Guru, Kasir, Pembeli, Arsitek, dll).

8) Menanam tumbuhan.

9) Opening Time - Gerak dan Lagu / Bhs Indonesia \& Inggris.

10) Dan lain-lain.

\section{E. Sentra Art (Seni)}

Sentra yang memberikan kesempatan pada anak untuk mengembangkan kemampuan menggunakan dan berinteraksi dengan berbagai alat dan bahan seni. Sentra seni dapat dibagi 
Al-Mudarris : Jurnal Ilmiah Pendidikan Islam Vol. 2, No. 2, November 2019, pp. 184 - 199

dalam seni musik, seni tari, seni kriya, atau seni pahat. Penentuan sentra seni yang dikembangkan tergantung pada kemampuan satuan PAUD. Sentra seni mengembangkan kemampuan motorik halus, keselarasan gerak, nada, aspek sosial-emosional dan lainnya. Kegiatan sentra seni yang biasanya dilakukan di TK Khalifah, diantaranya sebagai berikut:

1) Belajar alat musik angklung.

2) Belajar menari.

3) Belajar melukis.

4) Dan lain-lain.

\section{F. Sentra Sains}

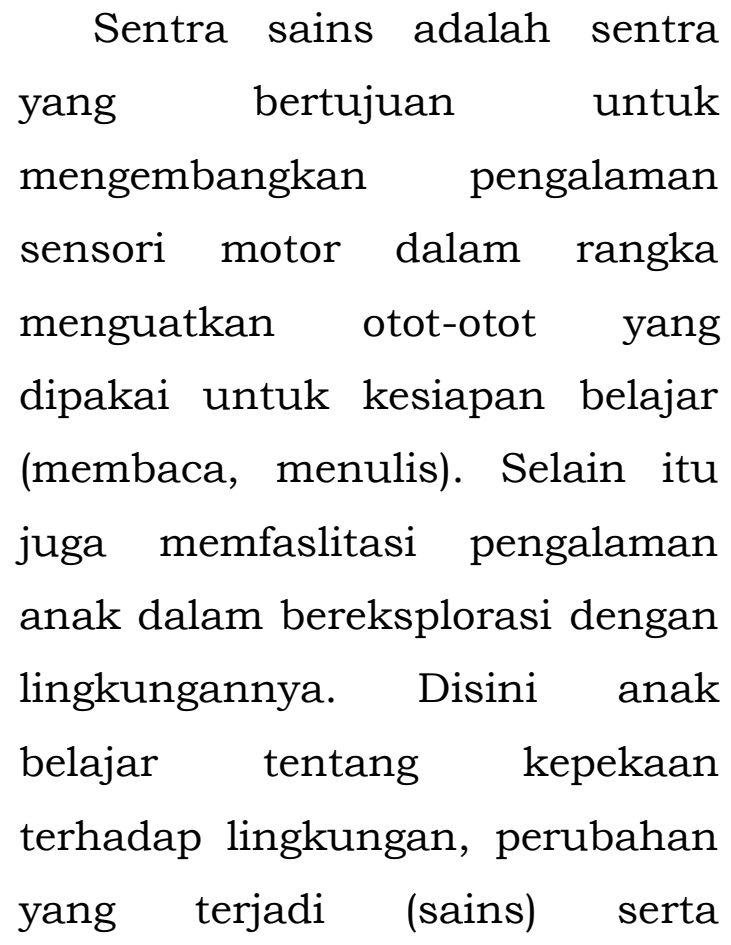

p-ISSN: 2622-1993

e-ISSN: 2622-1586

penguatan pembelajaran yang dialami di sentra.

Berikut ini adalah beberapa kegiatan yang pernah guru lakukan untuk menstimulus perkembangan anak dalam sentra sains:

1) Mengamati pertumbuhan tanaman.

2) Mengamati benda terapung dan tidak terapung di air.

3) Bereksplorasi mencampur warna.

4) Mengamati daun jatuh ke bawah (adanya gravitasi).

5) Belajar teknologi elektronik.

6) Dan lain-lain.

G. Sentra Exercise (olahraga/olah tubuh)

Sentra exercise (olahraga/olah tubuh) ialah sentra yang mengajak anak untuk melakukan gerakan-gerakan dan permainanpermainan yang bersifat fisik, untuk melatih kekuatan, kelenturan, kelincahan, koordinasi dan keseimbangan tubuh. Berikut ini adalah beberapa kegiatan yang pernah guru lakukan untuk menstimulus 
Al-Mudarris : Jurnal Ilmiah Pendidikan Islam Vol. 2, No. 2, November 2019, pp. 184 - 199

perkembangan anak dalam sentra exercise, yaitu:

1) Balon melayang.

2) Ular bergoyang.

3) Senam.

4) Permainan tradisional

5) Dan lain-lain

\section{H. Model Pembelajaran}

\section{Konsiderasi}

Model konsiderasi diciptakan oleh Peter McPhail yang ingin mengembangkan kepribadian anak menjadi manusia yang otentik dan kreatif. McPhail dengan tegas berkeberatan terhadap pendidikan moral yang terlampau rasional dan kognitif. Paul menganggap bahwa pembentukan moral tidak sama dengan pengembangan kognitif yang rasional (Pangabean dkk, 2007:84). Pembelajaran sikap pada dasarnya adalah membantu anak agar dapat mengembangkan kemampuan untuk bisa hidup bersama secara harmonis, peduli, dan merasakan apa yang dirasakan orang lain (tepo saliro) (Sanjaya, 80).

Model ini didasarkan atas hasil McPhail yang dilakukan
p-ISSN: 2622-1993

e-ISSN: 2622-1586

terhadap 800 siswa pria dan wanita yang berusia $13-18$ tahun tentang perlakuan baik dan perlakuan tidak baik yang dilakukan orang dewasa terhadap dirinya. Dan riset yang dilakukannya, McPhail menginterpretasikan bahwa kelakuan yang baik adalah kelakuan yang memperlihatkan kepedulian terhadap kebutuhan, perasaan dan perhatian orang lain.

McPhail berpendapat bahwa sekolah terlalu membebani siswa dengan penumpukan dan pemanipulasian informasi serta terlalu sedikit memberi perhatian pada kemampuan memecahkan persoalan sekitar identitas pribadi dan hubungan sosial. McPhail menyatakan bahwa siswa belajar lebih dari apa yang diajarkan gurunya. Belajar dari contoh-contoh adalah kunci bagi perkembangan individu secara alamiah. Contoh adalah suatu bentuk pendidikan. Tingkat berpikir moral yang lebih tinggi, maupun dalam perilaku moral 
Al-Mudarris : Jurnal Ilmiah Pendidikan Islam Vol. 2, No. 2, November 2019, pp. 184 - 199

perlu dimodelkan dalam situasi kehidupan nyata (Suharto, 2018).

Model pembelajaran konsiderasi sesuai dengan teori belajar humatistik. Menurut Carl Rogers aplikasi teori humanistik terhadap pembelajaran siswa lebih menunjuk pada ruh atau spirit selama proses pembelajaran yang mewarnai metode-metode yang diterapkan. Teori belajar humanistik lebih menekankan perlunya sikap saling menghargai dan tanpa prasangka (antara klien dan terapis) dalam membantu individu mengatasi masalah-masalah kehidupannya.

Selaras dengan pendapat di atas, Mohammad Syafei melalui Lembaga Pendidikan Kayutanam di Sumatra Barat, menolak model pendidikan barat yang hanya menekankan aspek kognitif. Syafei menginginkan peserta didiknya menjadi seorang ideal, yakni tertanam cita kebenaran dalam hatinya, dalam pengetahuan intelektualnya, dan dalam perilakunya sehari-hari. Syafei merupakan putra Marah Sultan, tokoh pergerakan politik
p-ISSN: 2622-1993

e-ISSN: 2622-1586

NIP di Padang, yang melanjutkan cita-cita perjuangan orang tuanya dalam bidang pendidikan. Pendidikan yang dibangunnya dapat mehasilkan manusia yang rajin dan ulet, serta memiliki kecakapan yang diperlukan sebagai bangsa yang bermartabat, dan memiliki kecintaan terhadap tanah air dan sesama manusia (Mulyasa, 2007:68).

I. Penerapan Model Konsiderasi Di Tk Khalifah Baciro Yogyakarta

Model pembelajaran konsiderasi merupakan model pembelajaran sikap. TK Khalifah Baciro salah satu TK Islam terbaik di Indonesia. TK Khalifah adalah TK yang menerapkan kurikulum berbasis Tauhid dan Entrepreneurship. TK Khalifah tidak hanya fokus untuk mengembangkan kemampuan anak dari segi kognitif dan psikomotor saja akan tetapi juga dari segi afektifnya juga. TK Khalifah mengajar anak-anak disana untuk memiliki akhlakul 
Al-Mudarris : Jurnal Ilmiah Pendidikan Islam Vol. 2, No. 2, November 2019, pp. 184 - 199

karimah, sopan santun dan budi pekerti yang baik dalam bersikap.

Agar model pembelajaran konsiderasi dapat terapkan dengan baik dan agar tercapainya tujuan dari pembelajaran konsiderasi yaitu agar anak menjadi manusia yang memiliki kepedulian terhadap orang lain. Karena kebutuhan yang fundamental pada manusia adalah bergaul secara harmonis dengan orang lain, saling memberi dan menerima dengan penuh cinta dan kasih sayang. Maka diperlukan metode pembelajaran yang sesuai untuk pembelajaran konsiderasi, berikut ini ada beberapa metode pembelajaran yang digunakan TK Khalifah dalam model pembelajaran konsiderasi:

\section{J. Metode Pola Pembiasaan}

Cara belajar sikap yang disebabkan dengan kebiasaan dapat menjadi dasar penanaman sikap tertentu terhadap suatu objek. Dalam proses pembelajaran di sekolah, baik secara disadari maupun tidak, guru dapat menanamkan sikap
p-ISSN: 2622-1993

e-ISSN: 2622-1586

tertentu kepada siswa melalui proses pembiasaan. Di TK Khalifah metode pembiasaan yang dilakukan misalnya seperti, anak dibiasakan saling tolong menolong kepada sesama contohnya anak yang sudah selesai mengerjakan tugas yang diberikan guru, diajarkan untuk menolong temannya kalau ada yang belum menyelesaikan tugasnya, selain itu juga anak diajarkan untuk terbiasa bersedekah kepada orang yang membutuhkan salah satu upaya yang dilakukan TK Khalifah adalah mengediakan tempat infaq untuk anak belajar bersedekah. TK Khalifah menanamkan nilai kepedulian moral kepada anak sebagai wujud syukur atas nikmat yang Allah Swt berikan kepada kita.

\section{K. Metode Modeling}

Pembelajaran sikap seseorang yang dilakukan melalui proses modeling yaitu pembentukan sikap melalui proses asimilasi atau proses mencontoh. Proses modeling ini adalah proses peniruan anak terhadap orang 
Al-Mudarris : Jurnal Ilmiah Pendidikan Islam Vol. 2, No. 2, November 2019, pp. 184 - 199

lain yang menjadi idolanya atau orang yang dihormatinya yang dimulai rasa kagum. Salah satu karakteristik anak didik yang sedang berkembang adalah keinginannya untuk melakukan peniruan (imitasi).

Anak merupakan peniru ulung karena anak belajar dari apa yang dilihat dan didengarnya. Maka dari itu kita sebagai orang dewasa diharapkan untuk hatihati dalam bertindak dihadapan anak. Di sekolah guru merupakan salah satu orang yang menjadi contoh bagi anak dalam melakukan sesuatu. Di TK Khalifah guru dituntut untuk memiliki akhlakul karimah agar memberikan contoh yang baik kepada anak. Metode modeling yang biasanya dilakukan di TK Khalifah, misalnya guru mencontohkan bagaimana cara bersikap kepada sesama dan masih banyak lagi sikap positif yang guru lakukan.

\section{Metode Bercerita}

$\begin{array}{ll}\text { Metode cerita merupakan } \\ \text { salah satu } & \text { pemberian } \\ \text { pengalaman belajar bagi anak }\end{array}$

p-ISSN: 2622-1993

e-ISSN: 2622-1586

dengan membawakan cerita kepada anak secara lisan. Bercerita dapat dilakukan dengan alat bantu (media) atau tanpa bantuan alat apapun. Metode bercerita adalah sebuah metode yang dapat menarik minat siswa dalam mempelajari suatu hal. Terlebih bila cerita disampaikan secara "wah". Metode cerita juga berfungsi untuk menambah perbendaharaan kata anak usia dini. Dalam melaksanakan pembelajaran konsiderasi agar lebih menyenangkan bisa juga diterapkan metode bercerita. TK Khalifah menerapkan metode bercerita dengan pemilihan cerita yang memfokuskan tentang pembelajaran sikap dan kepedulian moral.

Tidak dapat dipungkiri pemilihan cerita yang tepat akan sangat menentukan hasil dari pembelajaran tersebut. Salah satu contoh cerita yang pernah guru sampaikan kepada anak di TK Khalifah yaitu kisah nabi Muhammad Saw yang peduli terhadap fakir miskin tidak peduli fakir miskin tersebut 
Al-Mudarris : Jurnal Ilmiah Pendidikan Islam Vol. 2, No. 2, November 2019, pp. 184 - 199

beragama apa karena orang tersebut memang membutuhkan bantuan maka akan dibantu, padahal orang yang dibantu nabi Muhammad Saw malah menghina-hina beliau. Dari kisah tersebut tidak hanya diajarkan untuk membantu sesama akan tetapi juga, biarpun orang bersikap tidak baik kepada kita, kita tidak boleh membalas dengan sikap yang tidak baik juga akan tetapi balaslah dengan sikap baik.

Beberapa cerita yang TK Khalifah gunakan, yaitu tentang keteladanan para Nabi, dongeng tentang kepedulian terhadap sesama ataupun cerita yang dikarang sendiri oleh guru di TK Khalifah. Dalam melakukan metode bercerita guru melakukannya dengan menyenangkan agar menarik minat anak untuk mendengarkan cerita tersebut atau dengan menggunakan media seperti boneka tangan atau wayang.

Pembelajaran BCCT di TK Khalifah Yogyakarta diterapkan sesuai dengan teori yang
p-ISSN: 2622-1993

e-ISSN: 2622-1586

diungkapkan dengan Mukhtar Latif dkk dalam bukunuya "Orientasi Baru Pendidikan Anak Usia Dini: Teori dan Aplikasi". BCCT di TK Khalifah Baciro Yogyakarta sangat kreatif dengan mencetuskan nama-nama baru sentra, yaitu: sentra tauhid, keterampilan hidup/ lifeskill, seni/ art, sains dan olahraga atau olah tubuh. Selanjutnya pembelajaran BCCT di TK Khalifah juga berhasil mengembangkan aspek perkembangan anak. Dari subjek yang diteliti terdapat 2 anak yang aspek perkembangan baru memulai berkembang. Hal tersebut didukung dengan penelitian Eka Mandasari yang menyebutkan bahwa penerapan BCCT dapat meningkatkan multiple intelegen anak.

Pembelajaran konsiderasi di TK Khalifah Yogyakarta aspek perkembangan anak bukan hanya aspek kognitif, tetapi juga pada aspek afektif anak. Hal ini didukung dengan penelitian dari Suharto yang menyebutkan bahwa model pembelajaran 
Al-Mudarris : Jurnal Ilmiah Pendidikan Islam Vol. 2, No. 2, November 2019, pp. 184 - 199

konsiderasi memiliki pengaruh terhadap moral anak.

\section{KESIMPULAN}

Berdasarkan hasil penelitian dan pembahasan di atas disimpulkan bahwa pembelajaran BCCT dan Konsiderasi di TK Khalifah Baciro Yogyakarta berjalan secara optimal, dimana BCCT menggunakan 5 sentra sesuai dengan kebutuhan sekolah yang sesuai dengan tujuan sekolah tersebut. 5 sentra yang tersedia di TK Khalifah yaitu, tauhid, lifeskill (ketermapilan hidup), art (seni), sains dan exercise (olahraga/olah tubuh). Sedangkan pembelajaran konsiderasi memfokuskan pada aspek kogitif dan afekti anak agar memiliki akhlakul karimah, sopan santun dan budi pekerti yang baik dalam bersikap. Sehingga kedua model pembelajaran tersebut dapat dijadikan sebagai contoh untuk lembaga-lembaga pendidikan anak usia dini dalam memberikan stimulus terhadap aspek perkembangan anak.
p-ISSN: 2622-1993

e-ISSN: 2622-1586

\section{DAFTAR PUSTAKA}

Anam, Saiful. Jangan Remehkan Taman Kanak-Kanak Taman Yang Paling Indah. Yogyakarta: PT Wangsa Jatra Lestari, 2007.

Aziz, Abdul. "Implementasi Inovasi Pada Model-Model Pendidikan Anak Usia Dini Di Taman Pengasuhan Anak (TPA) Serama Kementrian Kesehatan RI.” JPUD - Jurnal Pendidikan Usia Dini 11, no. 2 (November 30, 2017): 201-14. https://doi.org/ 10.21009/JPUD .112 .01 .

Departemen Pendidikan Nasional. Pedoman Penerapan Pendekatan beyond Centers and Circle Time (BCCT) (Pendekatan Sentra Dan Lingkungan) Dalam Pendidikan Anak Usia Dini. Jakarta, 2006.

Gustini. "Pengaruh Model Pembelajaran Konsiderasi Terhadap Sikap Siswa Pad Pola Hidup Sehat Bersih Dan Sehat." UIN Syarif Hidayatullah Jakarta, 2011.

Hamzah, Nur. "Pelaksanaan Pembelajaran BCCT Bagi Anak Usia Dini: Study Pelaksanaan BCCT Di TK Islam Mujahidin 
Al-Mudarris : Jurnal Ilmiah Pendidikan Islam Vol. 2, No. 2, November 2019, pp. 184 - 199

Pontianak." At-Turats 10, no. 2 (July 19, 2016): 119-32. https://doi.org/10.24260/atturats.v10i2.668.

Martha Yuliana Agustiningsih, Dewi Gunawati, Winarno. "Pengaruh Model Pembelajaran Konsiderasi Terhadap Sikap Toleransi Siswa Pada Kompetensi Dasar Menghargai Keberagaman Suku, Agama, Ras Dan Antargolongan Dalam Bingkai Bhinneka Tunggal Ika." Educitizen 2, no. 2 (2018).

https://jurnal.fkip.uns.ac.id/in dex.php/civic/article/view/1190 5.

Martha Yuliana Agustiningsih, Dewi Gunawati \& Winarno. "Pengaruh Model Pembelajaran Konsiderasi Terhadap Sikap Toleransi Siswa Pada Kompetensi Dasar Menghargai Keberagaman Suku, Agama, Ras Dan Antargolongan Dalam Bingkai Bhinneka Tunggal Ika." Educitizen 2, no. 2 (2018).

Moleong, Lexy J., and Tjun. Surjaman. Metodologi Penelitian Kualitatif. Penerbit PT Remaja Rosdakarya, 2017.
p-ISSN: 2622-1993

e-ISSN: 2622-1586

Mulyasa, E. Manajemen PAUD. Bandung: PT Remaja Rosdakarya, 2014.

Mursid. Pengembangan Pembelajaran PAUD. Bandung: Remaja Rosda Karya, 2017.

Prastowo, Andi. Metode Penelitian Kualitatif Dalam Perspektif Rancangan Penelitian. Yogyakarta: Ar-Ruzz Media, 2011.

Prianggita, Veny Agustini. "Penerapan Model Konsiderasi Dan Pembentukan Rasional Dalam Pembelajaran.” MENDIDIK: Jurnal Kajian Pendidikan Dan Pengajaran 2, no. 1 (April 12, 2016): 72-80. https://doi.org/10.30653/003.2 01621.34 .

Saleh, Martini. Panduan Pendidikan Sentra Untuk PAUD. Jakarta: Pustaka Al-Falah, 2010.

Sanjaya, Wina. Strategi Pembelajaran Berorientasi Standar Proses Pendidikan. Jakarta: Prenada Media Group, 2010.

Sugiyono. Metode Penenlitian Kuantitatif Kualitatif Dan R\&D.

Bandung: Alfabeta, 2017.

Suharto. "Efektivitas Penerapan 
Al-Mudarris : Jurnal Ilmiah Pendidikan Islam Vol. 2, No. 2, November 2019, pp. 184 - 199

Model Pembelajaran Konsiderasi Untuk Meningkatkan Moral Peserta Didik Pada Mata Pelajaran Akidah Akhlak DI MTS. Madani Alauddin Pao-Pao Kab. Gowa." UIN Alauddin Makasar, 2018.

http:/ / repositori.uinalauddin.ac.id/8962/1/SUHART O.pdf.

Wibowo, Agus. Pendidikan Karakter Anak Usia Dini. Yogyakarta: Pustaka Pelajar, 2012.

Yulida, Dea, Nandi Warnandi, and
p-ISSN: 2622-1993

e-ISSN: 2622-1586

Dedy Kurniadi. "ModelL Konsiderasi Untuk Melatih Ketrampilan Sosial Anak Dengan Hambatan Emosi Dan Perilaku." JASSI ANAKKU 18, no. 2 (January 19, 2018): 15-21. http:// ejournal.upi.edu/index.p $\mathrm{hp} /$ jassi/article/view/9689.

Yusri Pangabean, Dkk. Strategi, Model, Dan Evaluasi, (Bandung: Bina Media Informasi. Bandung: Bina Media Informasi, 2007. 